\title{
1 Host ecology regulates interspecies recombination in bacteria of the genus 2 Campylobacter
}

4 Evangelos Mourkas ${ }^{1}$, Koji Yahara ${ }^{2}$, Sion C. Bayliss ${ }^{1}$, Jessica K. Calland ${ }^{1}$, Håkan Johansson ${ }^{3}$, 5 Leonardos Mageiros ${ }^{1}$, Zilia Y. Muñoz-Ramirez ${ }^{4}$, Grant Futcher $^{1}$, Guillaume Méric ${ }^{1 \#}$, 6 Matthew D. Hitchings ${ }^{5}$, Santiago Sandoval-Motta ${ }^{4}$, Javier Torres ${ }^{4}$, Keith A. Jolley ${ }^{6}$, Martin

7 C. J. Maiden ${ }^{6}$, Patrik Ellström ${ }^{7}$, Jonas Waldenström ${ }^{3}$, Ben Pascoe ${ }^{1}$, Samuel K. Sheppard ${ }^{1,6 *}$

$9{ }^{1}$ The Milner Centre for Evolution, Department of Biology and Biochemistry, University of Bath, Bath BA2

$107 \mathrm{AY}, \mathrm{UK} ;{ }^{2}$ Antimicrobial Resistance Research Center, National Institute of Infectious Diseases, Tokyo, $162-$

11 8640, Japan; ${ }^{3}$ Centre for Ecology and Evolution in Microbial Model Systems, Linnaeus University, Kalmar, 391

12 82, Sweden; ${ }^{4}$ Unidad de Investigacion en Enfermedades Infecciosas, UMAE Pediatria, Instituto Mexicano del

13 Seguro Social; ${ }^{5}$ Swansea University Medical School, Swansea University, Singleton Park, Swansea, SA2 8PP,

14 UK; ${ }^{6}$ Department of Zoology, University of Oxford, South Parks Road, Oxford, OX1 3PS, UK; ${ }^{7}$ Department of 15 Medical Sciences, Zoonosis Science Centre, Uppsala University, Uppsala, Sweden;

18 *Corresponding authors: Samuel K. Sheppard; s.k.sheppard@ bath.ac.uk

\#Present address: Cambridge Baker Systems Genomics Initiative, Baker Heart and Diabetes Institute, 75 Commercial Rd, Melbourne 3004, Victoria, Australia; Department of Infectious Diseases, Central Clinical School, Monash University, Melbourne, Victoria 3004, Australia.

Keywords: Campylobacter, genus, species, niche, adaptation, host, evolution.

26 Running title: Comparative genomics of the Campylobacter genus 


\section{Abstract}

29 Horizontal gene transfer (HGT) can allow traits that have evolved in one bacterial species to 30 transfer to another. This has potential to rapidly promote new adaptive trajectories such as

31 zoonotic transfer or antimicrobial resistance. However, for this to occur requires gaps to align

32 in barriers to recombination within a given time frame. Chief among these barriers is the

33 physical separation of species with distinct ecologies in separate niches. Within the genus

34 Campylobacter there are species with divergent ecologies, from rarely isolated single host

35 specialists to multi-host generalist species that are among the most common global causes of

36 human bacterial gastroenteritis. Here, by characterising these contrasting ecologies, we can

37 quantify HGT among sympatric and allopatric species in natural populations. Analysing

38 recipient and donor population ancestry among genomes from 30 Campylobacter species we

39 show that cohabitation in the same host can lead to a 6-fold increase in HGT between species.

40 This accounts for up to $30 \%$ of all SNPs within a given species and identifies highly

41 recombinogenic genes with functions including host adaptation and antimicrobial resistance.

42 As described in some animal and plant species, ecological factors are a major evolutionary

43 force for speciation in bacteria and changes to the host landscape can promote partial 44 convergence of distinct species through HGT. 


\section{Introduction}

It is well established that bacteria do not conform to a strict clonal model of reproduction but engage in regular horizontal gene transfer $(\mathrm{HGT})^{1}$. This lateral exchange of DNA can confer new functionality on recipient genomes, potentially promoting novel adaptive trajectories such as colonization of a new host or the emergence of pathogenicity ${ }^{2}$. In some cases, gene flow can occur at such magnitude, even between different species ${ }^{3,4}$, that one may question why disparate lineages do not merge and why distinct bacterial species exist at all ${ }^{5}$. An answer to this lies in considering the successive processes that enable genes from one strain to establish in an entirely new genetic background.

The probability of HGT is governed by the interaction of multiple factors, including exposure to DNA, the susceptibility of the recipient genome to DNA uptake, and the impact of recombined DNA on the recipient strain. These factors can be broadly defined in three functional phases and HGT can only occur when gaps align in each successive ecological, mechanistic and adaptive barriers within a given time frame (Fig. 1). In the first phase, the quantity of DNA available to recipient strains is determined by ecological factors such as the distribution, prevalence and interactions of donor and recipient bacteria, as well as the capacity for free DNA to be disseminated among species/strains. In the second phase, there are mechanistic barriers to HGT imposed by the homology dependence of recombination ${ }^{6}$ or other factors promoting DNA specificity - such as restriction-modification, CRISPR interference or antiphage systems ${ }^{7-11}$ - that can act as a defence against the uptake of foreign DNA (mechanistic barriers) $)^{12,13}$. Finally, the effect that HGT has on the fitness of the recipient cell in a given selective environment (adaptive barrier) will determine if the recombinant genotype survives for subsequent generations ${ }^{2,14}$.

Understanding how ecology maintains, and potentially confines, distinct strains and species has become increasingly important in the light of global challenges such as the emergence and spread of zoonotic pathogens ${ }^{15}$. A typical approach to investigating this is to consider spillover of particular strains or clones from one host to another (clonal transmission). This is an important phenomenon and may be influenced by anthropogenic change, such as habitat encroachment or agricultural intensification ${ }^{16}$. However, in many cases, important phenotypes, including antimicrobial resistance $(A M R)^{17-19}$, can be conferred by relatively few genes. In such cases, it may be important to consider how cohabiting strains and species can potentially draw genes from a common pangenome pool ${ }^{20-23}$ and how genes, rather than 
81 clones, can transition between segregated populations (gene pool transmission). To

82 investigate the impact of ecological segregation (ecological barriers) on this gene pool

83 transmission, in natural populations, requires quantification of HGT among sympatric and

84 allopatric bacteria.

86 Species within the genus Campylobacter are an ideal subject for considering how ecology

87 influences the maintenance of genetically distinct species for several reasons. First,

88 Campylobacter are a common component of the commensal gut microbiota of reptiles ${ }^{24,25}$,

89 birds $^{26,27}$ and mammals ${ }^{28}$ but, being microaerophilic, do not survive well outside of the host.

90 This creates island populations that have some degree of ecological isolation. Second,

91 because at least 12 species have been identified as human pathogens ${ }^{29}$ and $C$. jejuni and $C$.

92 coli among the most common global causes of bacterial gastroenteritis ${ }^{30}$, large numbers of

93 isolate genomes have been sequenced from potential reservoir hosts as part of public health

94 source tracking programs ${ }^{31,32}$. Third, within the genus there are species and strains that

95 inhabit one or multiple hosts (ecological specialists and generalists ${ }^{16,26,33-37}$ ). As a single host

96 can simultaneously carry multiple lineages ${ }^{38}$, possibly occupying different sub-niches within

97 that host ${ }^{39}$, there is potential to compare allopatric and sympatric populations. Finally, high

98 magnitude interspecies admixture (introgression) between $C$. jejuni and $C$. coli isolated from

99 agricultural animals suggests that host ecology plays a role in the maintenance of species ${ }^{40-43}$.

101 Here, we quantify HGT among 600 genomes from 30 Campylobacter species using a

102 'chromosome painting' approach ${ }^{44-46}$ to characterize shared ancestry among donor and

103 recipient populations. Specifically, we investigate the role of ecological barriers to

104 interspecies gene flow. By identifying recombining species pairs within the same and

105 different hosts we can describe interactions where co-localization enhances gene flow,

106 quantify the impact of ecological barriers in these populations and distinguish highly

107 recombinogenic genes that are found in multiple genetic backgrounds. This provides

108 information about the evolutionary forces that gave rise to species and the extent to which

109 ecological barriers maintain them as discrete entities.

\section{Results}

\section{Host restricted and host generalist Campylobacter species}

113 Isolate genomes were taken from publicly available databases to represent diversity within

114 the genus Campylobacter, including environmental isolates from the closely related 
115 Arcobacter and Sulfurospirillum species to provide phylogenetic context within the

116 Campylobacteraceae family (Supplementary Fig. 1). In total, there were 631 isolates from 30

117 different Campylobacter species (Fig. 2a) and 64 different sources, isolated from 31 different

118 countries between 1964 and 2016 (Supplementary Table 1). Among the isolates, 361 were $C$.

119 jejuni and C. coli and could be classified according to 31 Clonal Complexes (CCs) based

120 upon sharing four or more alleles at seven housekeeping genes defined by multi-locus

121 sequence typing (MLST) (Supplementary Table 1$)^{47}$ and were representative of known

122 diversity in both species ${ }^{16,33}$. The obligate human commensal and pathogen $C$. concisus

123 ( $n=106$ isolates), comprised 2 genomospecies (GSI, $n=32$ and GSII, $n=74$ ), as previously

124 described $^{48}$ (Supplementary Table 1). The collection also included more than 52 C. fetus

125 isolate genomes, including 3 subspecies: C. fetus subsp. fetus (n=8), C. fetus subsp.

126 venerealis $(\mathrm{n}=23)$ and $C$. fetus subsps. testudinum $(\mathrm{n}=21)(\text { Supplementary Table } 1)^{49}$. Two

127 clades were observed in C. lari (Supplementary Fig. 2) which could correspond to previously

128 described subspecies based on 16S rRNA sequencing ${ }^{50}$.

130 A maximum-likelihood phylogeny of the Campylobacter genus was reconstructed on a gene-

131 by-gene concatenated sequence alignment of 820 gene families shared by $>95 \%$ of all 132 isolates, with a core genome of 903,753 base pairs (Fig. 2a). The phylogeny included species 133 which appear to be restricted to one host or environment, including $C$. iguanorium ${ }^{51}$ and $C$. 134 geochelonis $^{52}$ (reptiles), C. lanienae $^{53}$ (pigs), C. hepaticus ${ }^{54}$ (chicken liver), C. lari group ${ }^{55}$ 135 (marine birds and environment) and $C$. pinnipediorum ${ }^{56}$ (seals) species, most of which were 136 discovered recently (Fig. 1, Supplementary Fig. 3). Host restricted species had lower 137 diversity possibly linked to low sample numbers, with $C$. hepaticus having the lowest 138 diversity (Supplementary Fig. 2) with 8/10 genomes associated with isolates from the same 139 outbreak $^{54}$. For other species there was evidence of a broad host range (ecological generalists) 140 (Fig. 1b). For example, highly structured C. jejuni and C. coli isolates were sampled from 141 seven and six host sources respectively (Fig. 1b, Supplementary Table 1, Supplementary Fig. 142 2, Supplementary Fig. 3). For C. fetus there was distinct separation between mammal143 associated C. fetus subsp fetus and C. fetus subsp venerealis and reptile-associated C. fetus 144 subsp testudinum (Supplementary Fig. 2) as previously described ${ }^{49}$. Unsurprisingly, a large 145 proportion of the isolates in this study were from humans, likely reflecting intensive 146 sampling. C. jejuni (27.52\%; $\mathrm{n}=60 / 218)$, C. coli $(14.68 \% ; \mathrm{n}=32 / 218)$ and C. concisus $(44.5 \%$; $147 \mathrm{n}=97 / 218$ ) were all common among human clinical samples. However, less common species 148 were also present, with nearly half of all Campylobacter species $(44.83 \%, \mathrm{n}=13 / 29)$ isolated 
149 from humans at least once (Fig. 1b, Supplementary Table 1). Agricultural animals were also a

150 common source accounting for more than $1 / 3$ of the isolates $(38.35 \% ; 242 / 631)$, with $10 / 30$

151 species isolated from more than one host species (Fig. 2b, Supplementary Table 1).

\section{Evidence of interspecies recombination in the core and accessory genome}

154 Genome size varied between 1.40 and 2.51 Mb (Supplementary Fig. 4) (mean 1.73) and the 155 number of genes (per isolate) ranged from 1,293 to 2,170 (mean 1,675) (Supplementary Fig.

156 5). The pangenome for the genus comprised 15,649 unique genes, found in at least one of the 157631 isolates (Fig. 1b), with 820 genes (5.24\% of the pangenome) shared by >95\% of all 158 isolates (core genome), across 30 species (Fig. 1b). We excluded species with fewer than 3 159 isolates in subsequent analysis. For the remaining 15 species the core genome ranged in size 160 from 1,116 genes in C. lari to 1,700 in C. geochelonis (Fig. 2a right panel). Differences were 161 also noted in the size of accessory genomes, with $C$. concisus (mean: 981 genes), $C$. 162 hyointestinalis (mean: 946 genes), C. showae (mean: 1,160 genes), C. geochelonis (mean: 1631,021 genes) and C. fetus (mean: 912 genes) containing the highest average number of 164 accessory genes (Fig. 3a left panel). Functional annotation of all 14,829 accessory genes 165 showed that $71 \%(10,561)$ encoded hypothetical proteins of unknown function due to the lack 166 of homology with well-characterized genes (Supplementary Fig. 6) ${ }^{57}$. Remaining genes were 167 related to metabolism, DNA modification, transporters, virulence, inner 168 membrane/periplasmic, adhesion, regulators, metal transport and antimicrobial resistance 169 (Supplementary Fig. 6).

171 To further understand genetic differentiation within and between species, we generated 172 genus-wide similarity matrices for the core and accessory genomes (Fig. 3c-d). For the core 173 genome, pairwise average nucleotide identity (ANI) was calculated for shared genes in all 174 possible genome pairs (Fig. 3c) using FastANI ${ }^{58}$. On average, isolates of the same species 175 shared $>95 \%$ similarity (Fig. 3c), with decreasing genetic similarity (between $85 \%$ and 90\%) 176 over greater phylogenetic distances. The number of core genome SNPs ranged from 983 to 177230,264 for the 15 Campylobacter species with $\geq 3$ isolates in our dataset, with $C$. coli and $C$. 178 concisus having the greatest mean SNP numbers (Supplementary Fig. 7a) indicating 179 considerable diversity within these species. In contrast C. hepaticus and C. geochelonis had 180 low mean SNP numbers with 986 and 4,310, respectively. This is likely related to low sample 181 numbers with isolates either sampled in close proximity ${ }^{52}$ or from a single outbreak ${ }^{54}$. 
183 The core genome similarity matrix provided initial evidence of interspecies gene flow

184 (introgression). This can be observed as elevated nucleotide identity between $C$. jejuni and

185 clade 1 C. coli (Fig. 3c), consistent with previous studies ${ }^{40,42,43}$. Further evidence of

186 introgression came from pairwise ANI comparison of genus-wide core genes, in all isolates

187 of the 15 major Campylobacter species, to the C. jejuni genome (Supplementary Fig. 7b). In

188 the absence of gene flow, isolates from the two species should have an approximately

189 unimodal ANI distribution reflecting accumulation of mutations throughout the genome. This

190 was largely the case but for some species, low nucleotide divergence suggested recent

191 recombination with $C$. jejuni. There was also evidence of interspecies accessory genome

192 recombination. Presence/absence patterns in the accessory genome matrix show considerable

193 accessory gene sharing among several species that was inconsistent with the phylogeny (Fig.

194 3d). This is well illustrated in C. lanienae where much of the accessory genome was shared

195 with other Campylobacter species (Fig. 3d).

197 Enhanced interspecies recombination among cohabiting species.

198 For Campylobacter inhabiting different host species there is a physical barrier to HGT.

199 However, when there is niche overlap, interspecies recombination can occur, for example

200 between $C$. jejuni and $C$. coli inhabiting livestock ${ }^{33,40,42}$. To understand the extent to which

201 inhabiting different hosts impedes interspecies gene flow we quantified recombination among

202 Campylobacter species where isolates originated from same host $\left(x_{1}, y\right)$ and different hosts

$203\left(x_{2}, y\right)($ Fig. 4a).

205 ChromoPainterV2 software was used to infer tracts of DNA donated from multiple donor 206 groups, belonging to the same CC but isolated from different hosts to recipient groups 207 (Materials and Methods). Among 27 combinations of multiple donor groups and recipient 208 groups, overall, there were more recombining SNPs within hosts than between hosts (Fig. 4b) 209 and for 10/27 species pairs there was evidence of enhanced within species recombination $210 \quad\left(x_{1} \rightarrow y>x_{2} \rightarrow y\right.$; Fig. 4c). To assess the robustness of the analysis we included the effect of 211 randomization and repeated the analysis by assigning random hosts for every strain 212 (Supplementary Fig. 8). In the 10 pair species comparisons where $x_{1} \rightarrow y>x_{2} \rightarrow y$, we detected 213 174,594 within-host recombining SNPs (mapped to 473 genes; 28.8\% of NCTC11168 genes) 214 and 109,564 between-host recombining SNPs (mapped to 395 genes; 24.05\% of NCTC11168 215 genes). From the 473 within-host recombining genes, 45 genes contained the highest number $216\left(>95^{\text {th }}\right.$ percentile) of recombining SNPs (Supplementary Fig. 9 and 10, Supplementary Table 
217 2). These genes have diverse inferred functions including metabolism, cell wall biogenesis,

218 DNA modification, transcription, and translation (Supplementary Table 2).

219

220 Interspecies recombination was observed for isolates sampled from chickens between 221 generalist lineages CC21 and CC45 (donors; C. jejuni) and generalist CC828 (recipient; $C$. 222 coli). These lineages appear to have high recombination to mutation $(r / m)$ ratio as inferred by 223 ClonalFrameML (Supplementary Table 3). DNA from generalist C. jejuni CC45 was 224 introduced into three Campylobacter species, including C. hepaticus (chicken), C. concisus 225 GSI and GSII (clinical) and C. ureolyticus (clinical) (Supplementary Table 4, Fig. 4c, 226 Supplementary Fig. 9 and 10). Clonal complex 45 had the highest $r / m$ ratio from all other lineages or species involved in the comparisons (Supplementary Table 3). There was increased recombination in genomes sampled from cattle between $C$. jejuni CC61 (donor; $C$. jejuni) and $C$. fetus and $C$. hyointestinalis (recipients) with $71.75 \%$ of all within-host 230 recombining SNPs from all 10 comparisons detected in these two pairs (Supplementary Table 231 4, Fig. 3c, Supplementary Fig. 9 and 10). Agricultural associated C. jejuni CC61 and C. fetus 232 subsp. venerealis involved in these comparisons were among the lineages and subspecies with the higehst $r / m$ ratios (Supplementary Table 3). The cattle-associated CC61 has previously been described as highly recombinant, and has been associated with rapid clonal expansion and adaptation in cattle ${ }^{16}$.

\section{The within-host mobilome}

238 Bacteria inhabiting the same niche may benefit from functionality conferred by similar gene

239 combinations. Recombination can promote the dissemination of adaptive genetic elements 240 among different bacterial species. Therefore, we postulated that the genes that recombine 241 most among species $\left(>95^{\text {th }}\right.$ percentile) will include those that are potentially beneficial in 242 multiple genetic backgrounds. To investigate this, we quantified mobility within the genome 243 identifying recombining SNPs found in more than one species comparison (Fig. 5a). These 244 SNPs mapped to 337 genes (20.52\% of the NCTC11168 genes; $2.15 \%$ of the pangenome) 245 (Fig. 5a, Supplementary Table 5). We found that 32 of those genes (9.49\%) have also been 246 found on plasmids (Supplementary Table 5). A total of 16 genes showed elevated within-host 247 interspecies recombination in more than five species pairs (Fig. 5a, Supplementary Table 5). 248 Genes included $c m e A$ and $c m e B$ which are part of the predominant efflux pump CmeABC 249 system in Campylobacter. Sequence variation in the drug-binding pocket of the cmeB gene 250 has been linked to increased efflux function leading to resistance to multiple drugs ${ }^{59}$. Many of 
251 the same antimicrobial classes are used in human and veterinary medicine and this may be

252 linked to selection for AMR Campylobacter, that are commonly isolated from livestock ${ }^{60}$. To investigate this further, we compared the genomes of all 631 isolates in our dataset to 8,762

254 known antibiotic resistance genes from the Comprehensive Antibiotic Resistance Database $255(\mathrm{CARD})^{61}$, ResFinder ${ }^{62}$ and the National Center for Biotechnology Information (NCBI) 256 databases. Homology (>75\%) was found for 42 AMR determinants associated with multi257 drug efflux pumps, aminoglycosides, tetracyclines and $\beta$-lactams (Supplementary Fig. 11). 258 Species that contained $>40 \%$ isolates from livestock, including C. jejuni, C. coli, C. lanienae, 259 C. hepaticus, C. hyointestinalis and C. fetus contained far more AMR determinants 260 (Supplementary Fig. 11). AMR genes are often collocated in the genome ${ }^{63}$ and our analysis revealed several gene clusters (Supplementary Fig. 12) that have been described in previous

262 studies $^{63,64}$. These findings are consistent with HGT-mediated circulation of AMR genes 263 among different Campylobacter species and support hypotheses that ecology drives gene pool transmission ${ }^{2,63}$.

Campylobacter host transmission and virulence have been linked with biofilm formation and changes into surface polysaccharides ${ }^{65,66}$. The $\operatorname{carB}$ gene showed elevated within-host interspecies recombination in eight species pair comparisons. This gene encodes a carbamoylphosphate synthase that has been associated with biosynthesis of substrates for many polysaccharides and is known to contain transposon insertion sites upstream of its genomic position $^{66}$. Other genes with elevated within-host interspecies transfer $(>7$ species pairs) included typA, a translator regulator for GTPase and gltX, a glutamate-tRNA ligase, promoting survival under stress conditions ${ }^{67,68}$. Other genes included gidA and hydB associated with virulence ${ }^{69}$ and hydrogenase enzyme activity (respiratory pathway in $C$. concisus, 69), respectively. By considering genes that overcome barriers to interspecies recombination and establish in multiple new genetic backgrounds, it may be possible to infer important phenotypes that allow bacteria to adapt to different hosts and environments.

\section{Discussion}

280 Phylogenetic reconstruction of the genus Campylobacter revealed a highly structured 281 population. Distinct core genome clustering largely supported known classification for 282 species, subspecies $\left(\right.$ C. fetus $\left.{ }^{49}\right)$, genomospecies $\left(\right.$ C. concisus, $\left.{ }^{48}\right)$ and clades $\left(\right.$ C. coll $\left.^{42}\right)$. Also 283 consistent with previous studies, certain species are principally associated with a specific host 284 niche. For example, C. fetus subsp testudinum, C. iguanorium, C. geochelonis were only 
285 sampled from reptile species, and C. pinnipediorum was only sampled from seals. However, 286 for several species there was clear evidence for host generalism, including C. jejuni, C. coli and C. lari, all of which were sampled from multiple hosts ${ }^{26,71}$. It is clear that the hosts with the greatest diversity of Campylobacter species were agricultural animals (and humans) (Fig. 2, Supplementary Fig. 3). While this undoubtedly reflects oversampling of these sources to some extent, the cohabitation of species in the same host niche potentially provides opportunities for interspecies HGT.

Initial evidence of interspecies gene flow came from comparison of average nucleotide identity (ANI) and the accessory genome gene presence/absence for all isolates. In each case, patterns of genetic similarity largely mirrored the phylogeny. However, consistent with previous studies $^{40}$, there was clear evidence of elevated homologous and non-homologous recombination between some species. For example, core genome ANI was higher between $C$. jejuni and $C$. coli clade 1, compared to other $C$. coli clades (Fig. 3c). The evidence for nonhomologous gene sharing was even more striking with accessory genome sharing across considerable genetic distances (Fig. 3d), exemplified by $C$. lanienae which shares accessory genes with most other Campylobacter species.

To quantify the extent to which ecological barriers influenced interspecies gene flow, it was necessary to focus on donor-recipient species pairs where there was evidence of elevated HGT in the same (sympatry) compared to different (allopatry) hosts. Perhaps unsurprisingly, this was not the case for all species comparisons. Interacting factors could lead to genetic isolation even when species inhabit the same host. First, rather than being a single niche, the host represents a collection of subniches with varying degrees of differentiation. For example, gut-associated bacteria in the same intestinal tract have been shown to occupy different microniches ${ }^{72}$ and more striking segregation may be expected between $C$. hepaticus inhabits the liver in poultry ${ }^{54}$ and gut-dwelling $C$. jejuni and $C$. coli in the same host. Second, there is potential for the resident microbiota to influence the colonization potential of different

313 Campylobacter species and therefore the opportunity for genetic exchange, for example

314 through succession $^{73}$ and inhibition of transient species by residents, as seen in some other 315 bacteria $^{74-76}$ in humans.

317 Continued exposition of the microecology of subniches is important but for 10 species 318 comparisons there was clear evidence of enhanced within-host gene flow allowing 
319 quantitative analysis of ecological barriers to gene flow. Specifically, there was on average a 3203 -fold increase in recombination among species pairs inhabiting the same host. In some 321 cases, this was greater, with 5-6 times more recombination among cohabiting species $C$. $322 j$ jejuni and C. hointestinalis/C. fetus in cattle. In absolute terms, this equates to approximately $32330 \%$ of all recorded SNPs in the recipient species being the result of introgression. To place 324 this in context, if greater than half $(51 \%)$ of the recorded SNPs resulted from interspecies 325 recombination then the forces of species convergence would be greater than those that 326 maintain distinct species. If maintained over time, these relative rates could lead to progressive genetic convergence unless countered by strong genome-wide natural selection

330 Quantitative SNP-based comparisons clearly ignore one very important factor. Specifically, 331 that recombined genes that do not reduce the fitness of the recipient genome (provide an 332 adaptive advantage) will remain in the population while others will be purged through natural 333 selection. Therefore, by identifying genomic hotspots of recombination and the putative 334 function of genes that recombine between species it is possible to understand more about micro-niche segregation and the host adapted gene pool. Of the 35 genes with evidence of enhanced within host HGT in $\geq 5$ species pairs, several were linked to functions associated with proliferation in, and exploitation of, the host. For example, the carB gene, encoding the large subunit of carbamoylphosphatase associated with polysaccharide biosynthesis, recombined in eight cohabiting species pairs and is potentially linked to enhanced virulence and growth ${ }^{66}$. In addition, other highly mobile genes, including typA and $g l t X$ are associated with survival and proliferation in stress conditions ${ }^{67,68}$, and hydB is linked to $\mathrm{NiFe}$ hydrogenase and nickel uptake that is essential for the survival of $C$. jejuni in the gut of birds and mammals ${ }^{77}$.

345 Some genes showed evidence of elevated recombination in a specific host species. For example, the glmS and napA genes in cohabiting Campylobacter species in cattle. In many bacteria, analogs of $g \operatorname{lm} S$ have multiple downstream integration specific sites $(\operatorname{Tn} 7)^{78}$ which

348 may explain the mobility of this gene. Explaining the mobility of napA is less straight 349 forward, but this gene is known to encode a nitrate reductase in Campylobacter $^{79}$ in 350 microaerobic conditions which may be ecologically significant as the accumulation of nitrate 351 in slurry, straw and drainage water can be potentially toxic to livestock mammals ${ }^{80}$. 
353 Factors such as host physiology, diet, and metabolism undoubtedly impose selection

354 pressures upon resident bacteria and the horizontal acquisition of genes provides a possible 355 vehicle for adaptation. However, the widespread use of antimicrobials by humans, and in pets 356 livestock production ${ }^{81,82}$, provides another major ecological barrier to niche colonization. We 357 found that gyrA was among the most recombinogenic genes in Campylobacter in chickens. 358 This is important as a single mutation in this gene is known to confer resistance to 359 ciprofloxacin $^{83}$. While the rising trend in fluorophinolone resistance in Campylobacter from 360 humans and livestock ${ }^{84}$ may result from spontaneous independent mutations, it is likely that it 361 is accelerated by HGT. Interspecies recombination of AMR genes has been observed between 362 C. jejuni and C. coli isolates from multiple sources including livestock, human and sewage ${ }^{63}$. 363 Consistent with this, we found AMR genes present in strains from 12 Campylobacter species 364 in multiple hosts (Supplementary Fig. 12). In some cases, strains from phylogenetically 365 closely related species (C. fetus and C. hyointestinalis) isolated from cattle, shared the same 366 AMR gene cluster (tet44 and ant(6)-Ib) described before in C. fetus subsp. fetus ${ }^{64}$, indicating 367 the circulation of colocalized AMR genes among related species and host niche gene pools. 368 Strikingly, the efflux pump genes $c m e A$ and $c m e B$, associated with multidrug resistance 369 (MDR) were highly mobile among Campylobacter species with evidence of elevated within 370 host interspecies recombination in $>7$ species pairs. Furthermore, the glt $X$ gene, which when phosphorylated by protein kinases promotes $\mathrm{MDR}^{68}$, was also among the most introgressed genes. While a deeper understanding of gene interactions, epistasis and epigenetics would be needed to prove that the lateral acquisition of AMR genes promotes niche adaptation, these data do suggest that HGT may facilitate colonization of antimicrobial-rich host environments, potentially favouring the spread of genes into multiple genetic backgrounds.

In conclusion, we show that species within the genus Campylobacter include those that are host restricted as well as host generalists. When species cohabit in the same host, ecological barriers to recombination can be perforated leading to considerable introgression between species. While the magnitude of introgession varies, potentially reflecting microniche structure with the host, there is clear evidence that ecology is important in maintaining genetically distinct species. This parallels evolution in some interbreeding eukaryotes, such as Darwin's Finches, where fluctuating environmental conditions can change the selection

385 Consistent with this, the host landscape is changing for Campylobacter, with intensively 386 reared livestock now constituting $60-70 \%$ of bird and mammal biomass on earth 
387 respectively ${ }^{87}$. This creates opportunities for species to be brought together in new adaptive

388 landscapes and for genes to be tested multiple genetic backgrounds. By understanding the

389 ecology of niche segregation and the genetics of bacterial adaptation we can hope to improve

390 strategies and interventions to reduce the risk of zoonotic transmission and the spread of

391 problematic genes among species.

\section{Materials \& Methods}

\section{Isolate genomes}

395 A total of 631 Campylobacter, 18 Arcobacter, eight Sulfurospirillum and five Helicobacter 396 genomes were assembled from previously published datasets (Supplementary Table S1). Isolates were sampled from clinical cases of campylobacteriosis and faeces of chickens, ruminants, wild birds, wild mammals, pets and environmental sources. Genomes and related metadata were uploaded and archived in the BIGS database ${ }^{88}$. All assembled genomes can be downloaded from FigShare (doi: 10.6084/m9.figshare.15061017). Comparative genomics analyses focused on the Campylobacter genomes representing 30 species including: $C$. avium $(\mathrm{n}=1) ; C$. coli $(\mathrm{n}=143) ; C$. concisus $(\mathrm{n}=106) ; C$. corcagiensis $(\mathrm{n}=1) ; C$. cuniculorum $(\mathrm{n}=2) ; C$. curvus $(\mathrm{n}=2) ; C$. fetus $(\mathrm{n}=52) ; C$. geochelonis $(\mathrm{n}=3) ; C$. gracilis $(\mathrm{n}=2) ; C$. helveticus $(\mathrm{n}=1) ; C$. hepaticus $(\mathrm{n}=10) ; C$. hominis $(\mathrm{n}=1) ; C$. hyointestinalis $(\mathrm{n}=16) ; C$. iguanorium $(\mathrm{n}=3) ; C$. insulaenigrae $(\mathrm{n}=1) ; C$. jejuni $(\mathrm{n}=218) ; C$. lanienae $(\mathrm{n}=26) ; C$. lari $(\mathrm{n}=13) ; C$. mucosalis $(\mathrm{n}=1) ; C$. ornithocola $(\mathrm{n}=1) ; C$. peloridis $(\mathrm{n}=1) ; C$. pinnipediorum $(\mathrm{n}=9) ; C$. rectus $(\mathrm{n}=1) ; C$. showae $(\mathrm{n}=3) ; C$. sputorum $(\mathrm{n}=1) ; C$. subantarcticus $(\mathrm{n}=3) ; C$. upsaliensis $(\mathrm{n}=3) ; C$. ureolyticus $(\mathrm{n}=4)$; C. volucris $(\mathrm{n}=2)$; Campylobacter $s p(\mathrm{n}=1)$ (Supplementary Table $\mathrm{S} 1)$.

\section{Pangenome characterization and phylogenetic analysis}

411 Sequence data were analysed using PIRATE, a fast and scalable pangenomics tool which 412 allows for orthologue gene clustering in divergent bacterial species ${ }^{89}$. Genomes were 413 annotated in Prokka ${ }^{90}$, using a genus database comprising well annotated $C$. jejuni strains 414 NCTC11168, 81116, 81-176 and M1, and plasmids pTet and pVir in addition to the already 415 existing databases used by Prokka ${ }^{90}$. Briefly, annotated genomes were used as input for 416 PIRATE. Non-redundant representative sequences were produced using CD-HIT and the 417 longest sequence was used as a reference for sequence similarity interrogation using 418 BLAST/DIAMOND. Gene orthologues were defined as "gene families" and were clustered 419 in different MCL thresholds, from 10 to $98 \%$ sequence identity (10, 20, 30, 40, 50, 60, 70, $42080,90,95,98)$. Higher MCL thresholds were used to identify allelic variation within different 
421 loci. An inflation value of 4 was used to increase the granularity of MCL clustering between

422 gene families. BLAST high-scoring pairs with a reciprocal minimum length of $90 \%$ of the

423 query/subject sequence were excluded from MCL clustering to reduce the number of spurious

424 associations between distantly related or conserved genes ${ }^{91}$. This information was used to

425 generate gene presence/absence and allelic variation matrices. A core gene-by-gene multiple

426 sequence alignment ${ }^{88}$ was generated using MAFFT $^{92}$ comprising genes shared $>95 \%$ of

427 isolates. Phylogenetic trees, based on core gene-by-gene alignments, were reconstructed

428 using the maximum-likelihood algorithm implemented in RAxML v8.2.11 ${ }^{93}$ with

429 GTRGAMMA as substitution model.

431 Quantifying core and accessory genome variation

432 The degree of genetic differentiation between species was investigated gene-by-gene as in

433 previous studies ${ }^{40,94}$ by calculating the average nucleotide identity (ANI) of all 631

434 Campylobacter genomes using FastANI v.1.0 ${ }^{58}$. The analysis generated a lower triangular

435 matrix with the lowest ANI value at 75\% (as computed by FastANI). A comparable gene

436 presence/absence matrix was produced using PIRATE and was further used to generate a

437 heatmap of accessory genome similarity based upon gene presence or absence. Subsequently,

438 all Campylobacter genomes were screened for the presence of antimicrobial resistance genes 439 against the $\mathrm{CARD}^{61}$, ResFinder ${ }^{62}$ and NCBI databases. All Campylobacter genomes were

440 further screened for the presence of plasmids using mobsuite ${ }^{95,96}$. A positive hit was defined

441 when a gene had $>75 \%$ nucleotide identity over $>50 \%$ of the sequence length. A gene

442 presence/absence matrix for every antimicrobial resistance gene was generated for every

443 genome. Genomes carrying AMR genes were screened to characterize the location of

444 adjacent genes using SnapGene software (GSL Biotech; available at snapgene.com), as

445 previously described ${ }^{63}$. The number of core SNPs was identified using SNP-sites (v2.3.2) ${ }^{97}$.

\section{Inference of recombination}

448 Each combination of a recipient group and multiple donor groups (belonging to the same CC

449 but isolated from different hosts) was selected to compare the extent of interspecies

450 recombination into the recipient genomes. Each donor group consisted of 8 isolates to avoid

451 the influence of difference in sample size on estimation of the extent of interspecies

452 recombination. Each recipient group included at least 4 isolates. We excluded $C$. jejuni and

453 C. coli clade 1 genomes isolated from seals and water, as these most likely represent spillover

454 events and not true host segregated populations. Briefly, we conducted a pairwise genome 
455 alignment between reference genome NCTC11168 and one of the strains included in the 456 donor-recipient analysis using progressiveMauve ${ }^{98}$. This enabled the construction of 457 positional homology alignments for all genomes regardless gene content and genome 458 rearrangements, which were then combined into a multiple whole-genome alignment, as 459 previously described ${ }^{99}$. ChromoPainterV2 software was used to calculate the amount of DNA 460 sequence that is donated from a donor to a recipient group ${ }^{45}$. ClonalFrameML ${ }^{100}$ was used to 461 infer the relative number of substitutions introduced by recombination $(r)$ and mutation $(m)$ 462 as the ratio $r / m$ as previously described ${ }^{16}$.

\section{Data availability}

465 Genomes sequenced as part of other studies are archived on the Short Read Archive associated with BioProject accessions: PRJNA176480, PRJNA177352, PRJNA342755, PRJNA345429， PRJNA312235， PRJNA415188， PRJNA524300， PRJNA528879， PRJNA529798, PRJNA575343, PRJNA524315 and PRJNA689604. Additional genomes were also downloaded from $\mathrm{NCBI}^{101}$ and pubMLST (http://pubmlst.org/campylobacter). Contiguous assemblies of all genome sequences compared are available at the public data repository Figshare (doi: 10.6084/m9.figshare.15061017) and individual project and accession numbers can be found in Supplementary Table 1.

\section{References}

475 1. Smith, J. M., Dowson, C. G. \& Spratt, B. G. Localized sex in bacteria. Nature 349, 29$476 \quad 31(1991)$.

477 2. Sheppard, S. K., Guttman, D. S. \& Fitzgerald, J. R. Population genomics of bacterial 478 host adaptation. Nat. Rev. Genet. 19, 549-565 (2018).

479 3. Shapiro, B. J., Leducq, J.-B. \& Mallet, J. What Is Speciation? PLOS Genet. 12, $480 \quad$ e1005860 (2016).

481 4. Doolittle, W. F. \& Zhaxybayeva, O. On the origin of prokaryotic species. Genome Res. 19, 744-756 (2009).

483 5. Doolittle, W. F. \& Papke, R. T. Genomics and the bacterial species problem. Genome 484 Biol. 7, 116 (2006).

485 6. Fraser, C., Hanage, W. P. \& Spratt, B. G. Recombination and the nature of bacterial 486 speciation. Science 315, 476-80 (2007).

487 7. Budroni, S. et al. Neisseria meningitidis is structured in clades associated with 488 restriction modification systems that modulate homologous recombination. Proc. Natl. 
Acad. Sci. 108, 4494-4499 (2011).

490 8. Oliveira, P. H., Touchon, M. \& Rocha, E. P. C. Regulation of genetic flux between bacteria by restriction-modification systems. Proc. Natl. Acad. Sci. 113, 5658-5663

493 9. Doron, S. et al. Systematic discovery of antiphage defense systems in the microbial pangenome. Science (80-. ). 359, eaar4120 (2018).

10. Nandi, T. et al. Burkholderia pseudomallei sequencing identifies genomic clades with distinct recombination, accessory, and epigenetic profiles. Genome Res. 25, 129-141 (2015).

11. Marraffini, L. A. \& Sontheimer, E. J. CRISPR Interference Limits Horizontal Gene Transfer in Staphylococci by Targeting DNA. Science (80-. ). 322, 1843-1845 (2008).

12. Thomas, C. M. \& Nielsen, K. M. Mechanisms of, and Barriers to, Horizontal Gene Transfer between Bacteria. Nat. Rev. Microbiol. 3, 711-721 (2005).

13. Eggleston, A. K., Mitchell, A. H. \& West, S. C. In Vitro Reconstitution of the Late Steps of Genetic Recombination in E. coli. Cell 89, 607-617 (1997).

14. Zhu, P. et al. Fit genotypes and escape variants of subgroup III Neisseria meningitidis during three pandemics of epidemic meningitis. Proc. Natl. Acad. Sci. 98, 5234-5239 (2001).

16. Mourkas, E. et al. Agricultural intensification and the evolution of host specialism in the enteric pathogen Campylobacter jejuni. Proc. Natl. Acad. Sci. 117, 11018-11028 (2020).

15. Boni, M. F. et al. Evolutionary origins of the SARS-CoV-2 sarbecovirus lineage

18. Schwarz, S. \& Johnson, A. P. Transferable resistance to colistin: a new but old threat.

J. Antimicrob. Chemother. 71, 2066-70 (2016).

19. Baker, K. S. et al. Horizontal antimicrobial resistance transfer drives epidemics of multiple Shigella species. Nat. Commun. 9, 1462 (2018). Microbiol. 24, 931-932 (2016).

21. McInerney, J. O., Whelan, F. J., Domingo-Sananes, M. R., McNally, A. \& O’Connell, M. J. Pangenomes and Selection: The Public Goods Hypothesis. in The Pangenome 
523 151-167 (Springer International Publishing, 2020). doi:10.1007/978-3-030-38281-0_7

524 22. Vos, M. \& Eyre-Walker, A. Are pangenomes adaptive or not? Nat. Microbiol. 2, 1576 $525 \quad$ (2017).

526 23. Werren, J. H. Selfish genetic elements, genetic conflict, and evolutionary innovation.

527 Proc. Natl. Acad. Sci. 108, 10863-10870 (2011).

528 24. Giacomelli, M. \& Piccirillo, A. Pet reptiles as potential reservoir of Campylobacter

529 species with zoonotic potential: TABLE 1: Vet. Rec. 174, 479.2-479 (2014).

530 25. Fitzgerald, C. et al. Campylobacter fetus subsp. testudinum subsp. nov., isolated from

531 humans and reptiles. Int. J. Syst. Evol. Microbiol. 64, 2944-2948 (2014).

532 26. Griekspoor, P. et al. Marked host specificity and lack of phylogeographic population

27. Atterby, C. et al. The Potential of Isolation Source to Predict Colonization in Avian Hosts: A Case Study in Campylobacter jejuni Strains From Three Bird Species. Front. Microbiol. 9, (2018).

28. Leatherbarrow, A. J. H. et al. Campylobacter lari $\square$ : genotype and antibiotic resistance

29. Man, S. M. The clinical importance of emerging Campylobacter species. Nat. Rev. of isolates from cattle, wildlife and water in an area of mixed dairy farmland in the

33. Sheppard, S. K. et al. Niche segregation and genetic structure of Campylobacter jejuni

34. Dearlove, B. L. et al. Rapid host switching in generalist Campylobacter strains erodes the signal for tracing human infections. ISME J. 10, 721-729 (2016). Geographic Variation. Appl. Environ. Microbiol. 76, 5269-5277 (2010).

555 36. Sheppard, S. K. et al. Cryptic ecology among host generalist Campylobacter jejuni in 556 domestic animals. Mol. Ecol. 23, 2442-2451 (2014). 
557 37. Woodcock, D. J. et al. Genomic plasticity and rapid host switching can promote the evolution of generalism: a case study in the zoonotic pathogen Campylobacter. Sci. Rep. 7, 9650 (2017).

38. Colles, F. M., Dingle, K. E., Cody, A. J. \& Maiden, M. C. J. Comparison of Campylobacter Populations in Wild Geese with Those in Starlings and Free-Range Poultry on the Same Farm. Appl. Environ. Microbiol. 74, 3583-3590 (2008).

39. Colles, F. M., McCarthy, N. D., Bliss, C. M., Layton, R. \& Maiden, M. C. J. The longterm dynamics of Campylobacter colonizing a free-range broiler breeder flock: an observational study. Environ. Microbiol. 17, 938-946 (2015).

40. Sheppard, S. K. et al. Progressive genome-wide introgression in agricultural

41. Taylor, A. J. et al. Cross-species evolutionary rewiring in the enteric bacterium Campylobacter. bioRxiv 2021.03.15.435406 (2021). doi:10.1101/2021.03.15.435406

42. Sheppard, S. K., McCarthy, N. D., Falush, D. \& Maiden, M. C. J. Convergence of Campylobacter Species: Implications for Bacterial Evolution. Science (80-. ). 320, 237-239 (2008). Structure using Dense Haplotype Data. PLoS Genet. 8, e1002453 (2012).

46. Yahara, K. et al. Chromosome Painting In Silico in a Bacterial Species Reveals Fine Population Structure. Mol. Biol. Evol. 30, 1454-1464 (2013).

47. Dingle, K. E. et al. Multilocus sequence typing system for Campylobacter jejuni. J.

48. Kirk, K. F. et al. Molecular epidemiology and comparative genomics of Campylobacter concisus strains from saliva, faeces and gut mucosal biopsies in inflammatory bowel disease. Sci. Rep. 8, 1902 (2018).

49. Iraola, G. et al. Distinct Campylobacter fetus lineages adapted as livestock pathogens and human pathobionts in the intestinal microbiota. Nat. Commun. 8, 1367 (2017). 50. Debruyne, L., On, S. L. W., De Brandt, E. \& Vandamme, P. Novel Campylobacter lari-like bacteria from humans and molluscs: description of Campylobacter peloridis 
591

592

593

594

595

596

597

598

599

600

601

602

603

604

605

606

607

608

609

610

611

612

613

614

615

616

617

618

619

620

621

622

623

624

sp. nov., Campylobacter lari subsp. concheus subsp. nov. and Campylobacter lari subsp. lari subsp. nov. Int. J. Syst. Evol. Microbiol. 59, 1126-32 (2009).

51. Gilbert, M. J., Kik, M., Miller, W. G., Duim, B. \& Wagenaar, J. A. Campylobacter iguaniorum sp. nov., isolated from reptiles. Int. J. Syst. Evol. Microbiol. 65, 975-982 (2015).

52. Piccirillo, A. et al. Campylobacter geochelonis sp. nov. isolated from the western Hermann's tortoise (Testudo hermanni hermanni). Int. J. Syst. Evol. Microbiol. 66, 3468-3476 (2016).

53. Logan, J. M. J., Burnens, A., Linton, D., Lawson, A. J. \& Stanley, J. Campylobacter lanienae sp. nov., a new species isolated from workers in an abattoir. Int. J. Syst. Evol. Microbiol. 50, 865-872 (2000).

54. Van, T. T. H., Elshagmani, E., Gor, M. C., Scott, P. C. \& Moore, R. J. Campylobacter hepaticus sp. nov., isolated from chickens with spotty liver disease. Int. J. Syst. Evol. Microbiol. 66, 4518-4524 (2016).

55. Miller, W. G. et al. Comparative genomics of the Campylobacter lari group. Genome Biol. Evol. 6, 3252-66 (2014).

56. Gilbert, M. J. et al. Campylobacter pinnipediorum sp. nov., isolated from pinnipeds, comprising Campylobacter pinnipediorum subsp. pinnipediorum subsp. nov. and Campylobacter pinnipediorum subsp. caledonicus subsp. nov. Int. J. Syst. Evol. Microbiol. 67, 1961-1968 (2017).

57. Pascoe, B. et al. Domestication of Campylobacter jejuni NCTC 11168. Microb. genomics 5, (2019).

58. Jain, C., Rodriguez-R, L. M., Phillippy, A. M., Konstantinidis, K. T. \& Aluru, S. High throughput ANI analysis of $90 \mathrm{~K}$ prokaryotic genomes reveals clear species boundaries. Nat. Commun. 9, 5114 (2018).

59. Yao, H. et al. Emergence of a Potent Multidrug Efflux Pump Variant That Enhances Campylobacter Resistance to Multiple Antibiotics. MBio 7, 1-11 (2016).

60. Livermore, D. M. Introduction: the challenge of multiresistance. Int. J. Antimicrob. Agents 29, S1-S7 (2007).

61. Jia, B. et al. CARD 2017: expansion and model-centric curation of the comprehensive antibiotic resistance database. Nucleic Acids Res. 45, D566-D573 (2017).

62. Zankari, E. et al. Identification of acquired antimicrobial resistance genes. $J$. Antimicrob. Chemother. 67, 2640-2644 (2012).

63. Mourkas, E. et al. Gene pool transmission of multidrug resistance among 
625

626

627

628

629

630

631

632

633

634

635

636

637

638

639

640

641

642

643

644

645

646

647

648

649

650

651

652

653

654

655

656

657

658

Campylobacter from livestock, sewage and human disease. Environ. Microbiol. 21, 4597-4613 (2019).

64. Abril, C., Brodard, I. \& Perreten, V. Two Novel Antibiotic Resistance Genes, tet(44) and ant(6)-Ib, Are Located within a Transferable Pathogenicity Island in Campylobacter fetus subsp. fetus. Antimicrob. Agents Chemother. 54, 3052-3055 (2010).

65. Szymanski, C. M., Logan, S. M., Linton, D. \& Wren, B. W. Campylobacter - a tale of two protein glycosylation systems. Trends Microbiol. 11, 233-238 (2003).

66. McLennan, M. K. et al. Campylobacter jejuni Biofilms Up-Regulated in the Absence of the Stringent Response Utilize a Calcofluor White-Reactive Polysaccharide. J. Bacteriol. 190, 1097-1107 (2008).

67. Margus, T., Remm, M. \& Tenson, T. Phylogenetic distribution of translational GTPases in bacteria. BMC Genomics 8, 1-18 (2007).

68. Semanjski, M. et al. The kinases HipA and HipA7 phosphorylate different substrate pools in Escherichia coli to promote multidrug tolerance. Sci. Signal. 11, (2018).

69. Mikheil, D. M., Shippy, D. C., Eakley, N. M., Okwumabua, O. E. \& Fadl, A. A. Deletion of gene encoding methyltransferase ( $\mathrm{gidB}$ ) confers high-level antimicrobial resistance in Salmonella. J. Antibiot. (Tokyo). 65, 185-192 (2012).

70. Benoit, S. L. \& Maier, R. J. Site-directed mutagenesis of Campylobacter concisus respiratory genes provides insight into the pathogen's growth requirements. Sci. Rep. 8, 14203 (2018).

71. Cody, A. J. et al. Wild bird-associated Campylobacter jejuni isolates are a consistent source of human disease, in Oxfordshire, United Kingdom. Environ. Microbiol. Rep. 7, 782-788 (2015).

72. Hayashi, H., Takahashi, R., Nishi, T., Sakamoto, M. \& Benno, Y. Molecular analysis of jejunal, ileal, caecal and recto-sigmoidal human colonic microbiota using 16S rRNA gene libraries and terminal restriction fragment length polymorphism. J. Med.

Microbiol. 54, 1093-1101 (2005).

73. Lu, J. et al. Diversity and succession of the intestinal bacterial community of the maturing broiler chicken. Appl. Environ. Microbiol. 69, 6816-24 (2003).

74. Stecher, B. et al. Like will to like: abundances of closely related species can predict susceptibility to intestinal colonization by pathogenic and commensal bacteria. PLoS Pathog. 6, e1000711 (2010).

75. van Elsas, J. D. et al. Microbial diversity determines the invasion of soil by a bacterial 
659

660

661

662

663

664

665

666

667

668

669

670

671

672

673

674

675

676

677

678

679

680

681

682

683

684

685

686

687

688

689

690

691

692

pathogen. Proc. Natl. Acad. Sci. U. S. A. 109, 1159-64 (2012).

76. Nowrouzian, F. L., Wold, A. E. \& Adlerberth, I. Escherichia coli strains belonging to phylogenetic group B2 have superior capacity to persist in the intestinal microflora of infants. J. Infect. Dis. 191, 1078-83 (2005).

77. Howlett, R. M., Hughes, B. M., Hitchcock, A. \& Kelly, D. J. Hydrogenase activity in the foodborne pathogen Campylobacter jejuni depends upon a novel ABC-type nickel transporter (NikZYXWV) and is SlyD-independent. Microbiology 158, 1645-1655 (2012).

78. Choi, K.-H. Applications of Transposon-Based Gene Delivery System in Bacteria. $J$. Microbiol. Biotechnol. 19, 217-28 (2009).

79. Pittman, M. S. et al. Growth of Campylobacter jejuni on nitrate and nitrite: electron transport to NapA and NrfA via NrfH and distinct roles for NrfA and the globin Cgb in protection against nitrosative stress. Mol. Microbiol. 63, 575-590 (2007).

80. Alexander, J. et al. Nitrite as undesirable substances in animal feed $\square$ Scientific Opinion of the Panel on Contaminants in the Food Chain. EFSA J. 7, 1-47 (2009).

81. Teuber, M. Veterinary use and antibiotic resistance. Curr. Opin. Microbiol. 4, 493-499 (2001).

82. Price, L. B., Koch, B. J. \& Hungate, B. A. Ominous projections for global antibiotic use in food-animal production. Proc. Natl. Acad. Sci. U. S. A. 112, 5554-5 (2015).

83. Luo, N., Sahin, O., Lin, J., Michel, L. O. \& Zhang, Q. In Vivo Selection of Campylobacter Isolates with High Levels of Fluoroquinolone Resistance Associated with gyrA Mutations and the Function of the CmeABC Efflux Pump. Antimicrob. Agents Chemother. 47, 390-394 (2003).

84. Sproston, E. L., Wimalarathna, H. M. L. \& Sheppard, S. K. Trends in fluoroquinolone resistance in Campylobacter. Microb. Genomics 4, 1-8 (2018).

85. Mallet, J. Hybrid speciation. Nature 446, 279-283 (2007).

86. Grant, P. R. \& Grant, B. R. Hybridization of Bird Species. Science (80-. ). 256, $193-$ 197 (1992).

87. Bar-On, Y. M., Phillips, R. \& Milo, R. The biomass distribution on Earth. Proc. Natl. Acad. Sci. 115, 6506-6511 (2018).

88. Sheppard, S. K., Jolley, K. A. \& Maiden, M. C. J. A Gene-By-Gene Approach to Bacterial Population Genomics: Whole Genome MLST of Campylobacter. Genes (Basel). 3, 261-277 (2012).

89. Bayliss, S. C., Thorpe, H. A., Coyle, N. M., Sheppard, S. K. \& Feil, E. J. PIRATE: A 
693

694

695

696

697

698

699

700

701

702

703

704

705

706

707

708

709

710

711

712

713

714

715

716

717

fast and scalable pangenomics toolbox for clustering diverged orthologues in bacteria. Gigascience 8, 1-9 (2019).

90. Seemann, T. Prokka: rapid prokaryotic genome annotation. Bioinformatics 30, 20682069 (2014).

91. Sahl, J. W., Caporaso, J. G., Rasko, D. A. \& Keim, P. The large-scale blast score ratio (LS-BSR) pipeline: a method to rapidly compare genetic content between bacterial genomes. PeerJ 2, e332 (2014).

92. Katoh, K. MAFFT: a novel method for rapid multiple sequence alignment based on fast Fourier transform. Nucleic Acids Res. 30, 3059-3066 (2002).

93. Stamatakis, A. RAxML version 8: a tool for phylogenetic analysis and post-analysis of large phylogenies. Bioinformatics 30, 1312-1313 (2014).

94. Didelot, X., Achtman, M., Parkhill, J., Thomson, N. R. \& Falush, D. A bimodal pattern of relatedness between the Salmonella Paratyphi A and Typhi genomes: convergence or divergence by homologous recombination? Genome Res. 17, 61-8 (2007).

95. Robertson, J. \& Nash, J. H. E. MOB-suite: software tools for clustering, reconstruction and typing of plasmids from draft assemblies. Microb. genomics 4, (2018).

96. Robertson, J., Bessonov, K., Schonfeld, J. \& Nash, J. H. E. Universal whole-sequencebased plasmid typing and its utility to prediction of host range and epidemiological surveillance. Microb. Genomics 6, 1-12 (2020).

97. Page, A. J. et al. SNP-sites: rapid efficient extraction of SNPs from multi-FASTA alignments. Microb. Genomics 2, e000056 (2016).

98. Darling, A. E., Mau, B. \& Perna, N. T. progressiveMauve: Multiple Genome Alignment with Gene Gain, Loss and Rearrangement. PLoS One 5, e11147 (2010).

99. Yahara, K. et al. Genomic surveillance of Neisseria gonorrhoeae to investigate the distribution and evolution of antimicrobial-resistance determinants and lineages. Microb. Genomics 4, 1-3 (2018).

100. Didelot, X. \& Wilson, D. J. ClonalFrameML: Efficient Inference of Recombination in Whole Bacterial Genomes. PLOS Comput. Biol. 11, e1004041 (2015).

101. NCBI Resource Coordinators. Database resources of the National Center for Biotechnology Information. Nucleic Acids Res. 44, D7-D19 (2016).

\section{Acknowledgements}


726 This work was supported by Wellcome Trust grants 088786/C/09/Z and Medical Research

727 Council (MRC) grants MR/M501608/1 and MR/L015080/1 awarded to S.K.S.

\section{Competing interests}

730 The authors declare no competing interests.

\section{Figure legends}

733 Fig. 1. Barriers to horizontal gene transfer in bacteria. A series of barriers must be 734 surmounted for DNA to transmit from one species to another. These are broadly defined in 735 three categories. At a given time, alignment of holes in successive barriers is necessary for 736 HGT to occur. Here we focus on ecological barriers that are influenced by multiple factors 737 that reflect the physical isolation of bacteria in separate niches.

Fig. 2. Population structure and host ecology in the genus Campylobacter. a,

740 Phylogenetic tree of 631 Campylobacter isolates from 30 species reconstructed using a gene-

741 by-gene concatenated alignment of 820 core genes (shared by $>95 \%$ of isolates) and an 742 approximation of the maximum-likelihood algorithm (ML) implemented in RAxML. The

743 species name is indicated adjacent to the associated sequence cluster. The scale bar indicates 744 the estimated number of substitutions per site. b, Isolation source of Campylobacter species with $\mathrm{n} \geq 3$ isolates.

Fig. 3. Core and accessory genome variation in the genus Campylobacter. a, Overall distribution of the total number of accessory genes (left) and core genes (right) per isolate for each Campylobacter species (where $\mathrm{n} \geq 3$ isolates). The number of accessory genes is shown as boxplots (min to max). b, Venn diagram of pangenomes among different Campylobacter species $(n \geq 9)$. The number of core genes shared by all species is illustrated in the center. $\mathbf{c}$,

752 Pairwise average nucleotide identity comparison calculated for all 631 Campylobacter 753 isolates based upon 820 core genes shared by $>95 \%$ of isolates. ANI values $<75 \%$ are not 754 calculated by FastANI ${ }^{58}$. d, Pairwise accessory genome similarity based upon gene presence 755 or absence at 2,168 non-core loci. The heatmaps coloring ranges from yellow (minimum) to 756 red (maximum). The matrices are ordered according to the phylogenetic tree presented in Fig.

757 2a. Different colours correspond to Campylobacter species with $\geq 3$ isolates. 
759 Fig. 4. Elevated within-host interspecies recombination and donor-recipient

760 comparisons. a, A hypothesis depicting the relationships between Campylobacter species, $C$.

761 jejuni $\left(x_{1}, x_{2}\right)$ and $C$. coli $(y)$, when found in the same or in different hosts. b, Number of

762 recombining SNPs within and between host as inferred by chromosome painting analysis for

763 all donor recipient species comparisons. The error bar represents the standard error of the

764 mean (SEM). c, The figure shows the number of donated SNPs in 10 donor-recipient pair

765 species comparisons. The proportion (\%) of recombining SNPs with $>90 \%$ probability of

766 copying from a donor to a recipient genome is illustrated in the $y$ axis. All donor groups are

767 shows in the $x$ axis. All coloured boxes correspond to comparison where donors and

768 recipients are found in the same host.

769

770 Fig. 5. The mobilome of the Campylobacter genus. a, The graph illustrates the proportion of 771 recombining genes in 10 different species comparisons. The number of species pairs in which

772 the gene was found to recombine is shown on the $x$ axis and the number of genes in each

773 category is given on the $y$ axis and. The exact number of genes found in each group

774 comparison is shown on the top of each box. b, Number of Campylobacter species

775 harbouring AMR genes that belong to efflux pumps and four different antibiotic classes

776 which are shown on the $x$ axis. c, The circos plot indicates the 16 genes involved in

777 recombination in $>5$ donor-recipient pair species comparisons. Gene matches are indicated by

778 joining lines, coloured differently for each gene. Gene names are shown around the perimeter

779 for each Campylobacter species. d, The circos plot indicates the sharing of AMR genes

780 associated with efflux pumps and four antibiotic classes among Campylobacter species.

781 Presence of at least one gene (not necessarily the same gene) conferring resistance to a

782 specific antibiotic class is indicated by joining lines, coloured differently for each drug class.

783 Efflux pumps (i), $\beta$-lactams (ii), tetracyclines (iii), aminoglycosides (iv) and lincosamides (v)

784 are shown around the perimeter for each Campylobacter species. 
bioRxiv preprint doi: https://doi.org/10.1101/2021.08.24.457495; this version posted August 24, 2021. The copyright holder for this preprint (which was not certified by peer review) is the author/funder, who has granted bioRxiv a license to display the preprint in perpetuity. It is made available under aCC-BY-NC-ND 4.0 International license.

ECOLOGICAL BARRIER MECHANISTIC BARRIER ADAPTIVE BARRIER

Host biogeography, Factors promoting DNA

distribution, prevalence

specificity including

Fitness of the recombinant

behaviour and interactions.

genotype in a given niche.

Sub-niche segregation.

recombination, restriction-

modification systems.

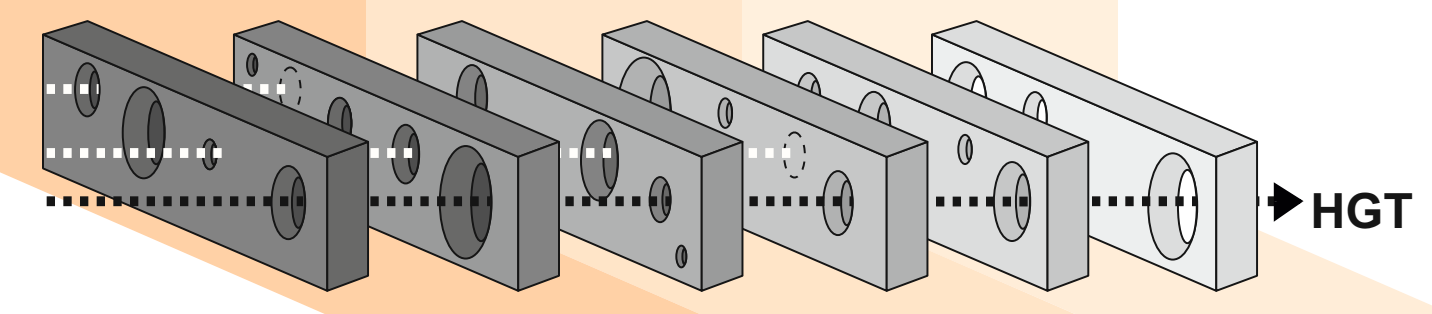


bioRxiv preprint doi: https://doi.org/10.1101/2021.08.24.457495; this version posted August 24, 2021. The copyright holder for this preprint (which was not certifiedplepgeficr review) is the author/funder, who has granted bioRxiv a license to display the preprint in perpetuity. It is made

$$
\text { c. jejuni } \bigcirc \text { C. coli }
$$

C. cunniculorum

c. upsaliensis 2
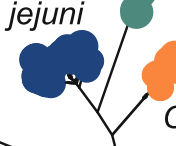

C. subantarcticus

C. helveticus

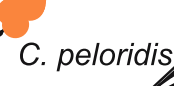

C. lari

90 C. ornithocola

$\mathrm{O}$ C. insulaenigrae

C. volucris

C. avium<smiles>C1CC2CCCC2C1</smiles>

$\checkmark$

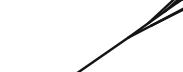
0 International license.

C. coli clade $1(n=103)$

C. coli clade $2(n=19)$

C. coli clade $3(n=18)$

C. jejuni $(n=218)$

C. concisus $(n=106)$

C. fetus $(n=52)$

C. Ianienae $(n=26)$

C. hepaticus $(\mathrm{n}=10)$

C. hyointestinalis $(n=16)$

C. pinnipediorum $(\mathrm{n}=9)$

C. lari $(\mathrm{n}=13)$

C. geochelonis $(n=3)$

C. ureolyticus $(n=4)$

C. upsaliensis $(n=3)$

C. showae $(\mathrm{n}=3)$

C. subantarcticus $(n=3)$

C. iguanorium $(n=3)$

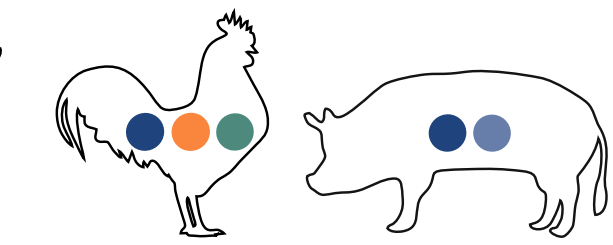

C. concisus

C. mucosalis

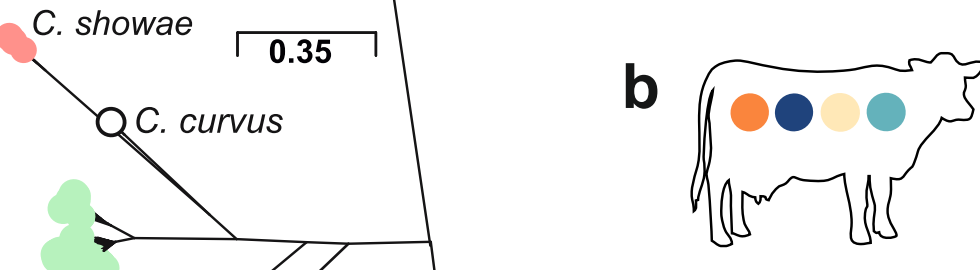

C. pinnipediorum

C. iguanorium C. fetus subs testudinum

C. fetus subs fetus
C. fetus subs venerealis

C. hyiontestinalis

C. geochelonis

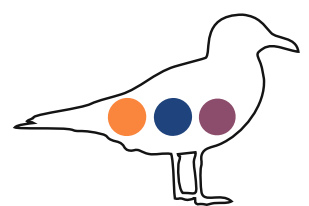

C. ureolyticus

C. corcagiensis

C. lanienae

8 C. corcagie
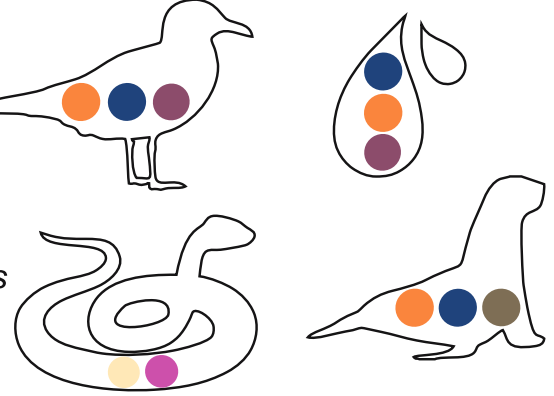

C. gracilis

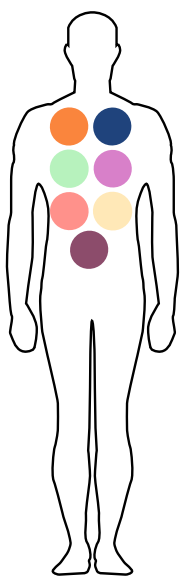


a

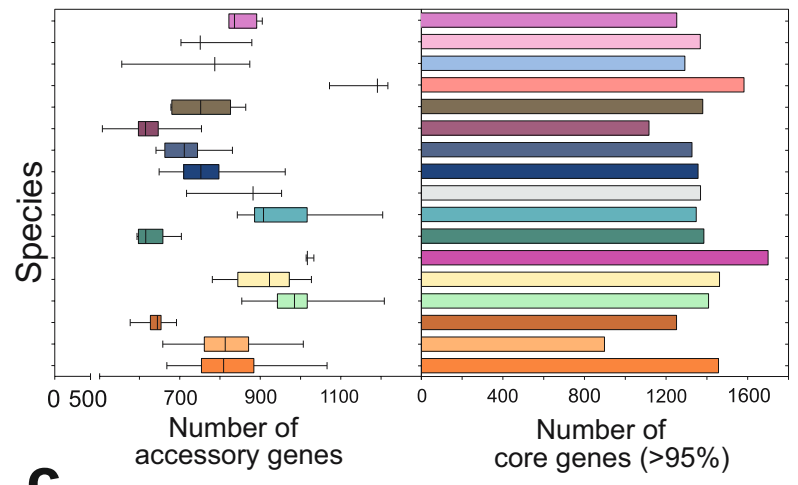

b

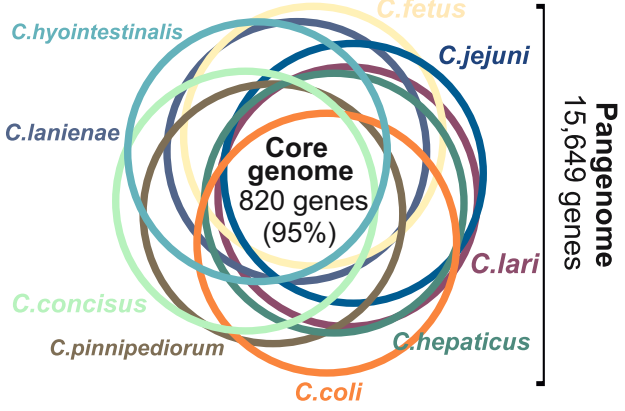

d

Accessory genome

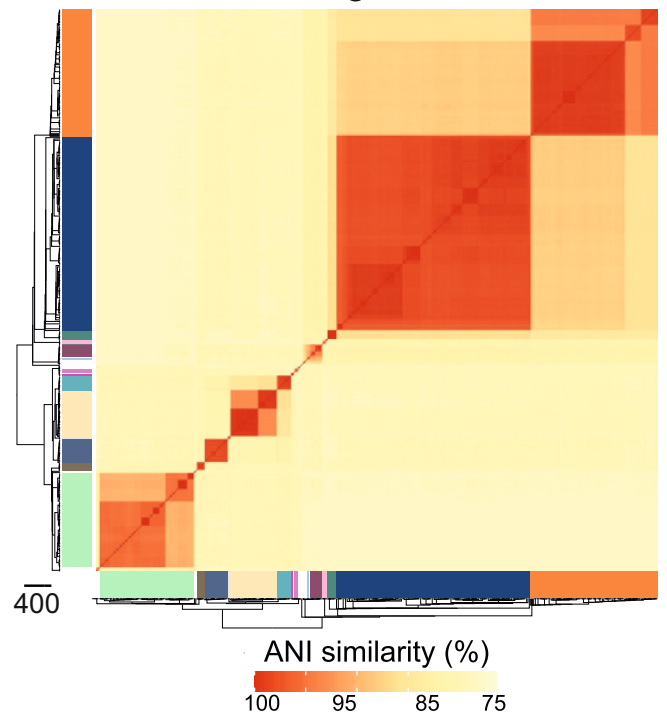

C. coli clade $1(n=103)$

C. coli clade $2(\mathrm{n}=19)$

C. coli clade $3(\mathrm{n}=18)$

C. jejuni $(\mathrm{n}=218)$

C. $\operatorname{concisus}(\mathrm{n}=106)$

C. fetus $(\mathrm{n}=52)$

\begin{tabular}{l}
$\square$ \\
\hline- \\
\hline
\end{tabular}

C. lanienae $(\mathrm{n}=26$

C. hepaticus $(\mathrm{n}=10)$

C. hyointestinalis $(n=16)$

C. pinnipediorum $(\mathrm{n}=9)$

C. Iari $(n=13)$

C. geochelonis $(n=3)$

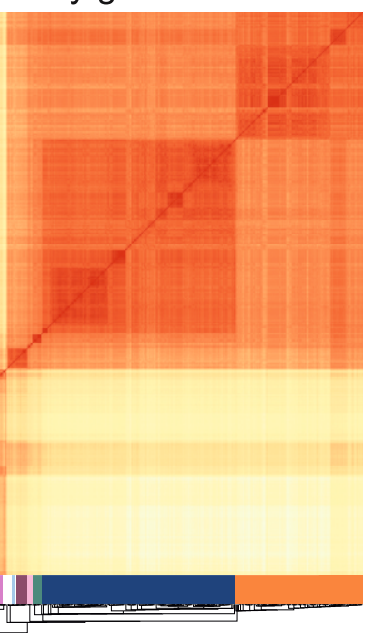

Shared presence matrix similarity

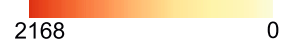

C. ureolyticus $(n=4)$

C. upsaliensis $(\mathrm{n}=3)$

C. showae $(\mathrm{n}=3)$

C. subantarcticus $(\mathrm{n}=3)$

C. iguanorium $(\mathrm{n}=3)$ 
bioRxiv preprint doi: https://doi.org/10.1101/2021.08.24.457495; this version posted August 24, 2021. The copyright holder for this preprint (which was not certified by peer review) is the author/funder, who has granted biokxiy a license to display the preprint in perpetuity. It is made 2 available under aCC-BY-NC- 10 the International license.
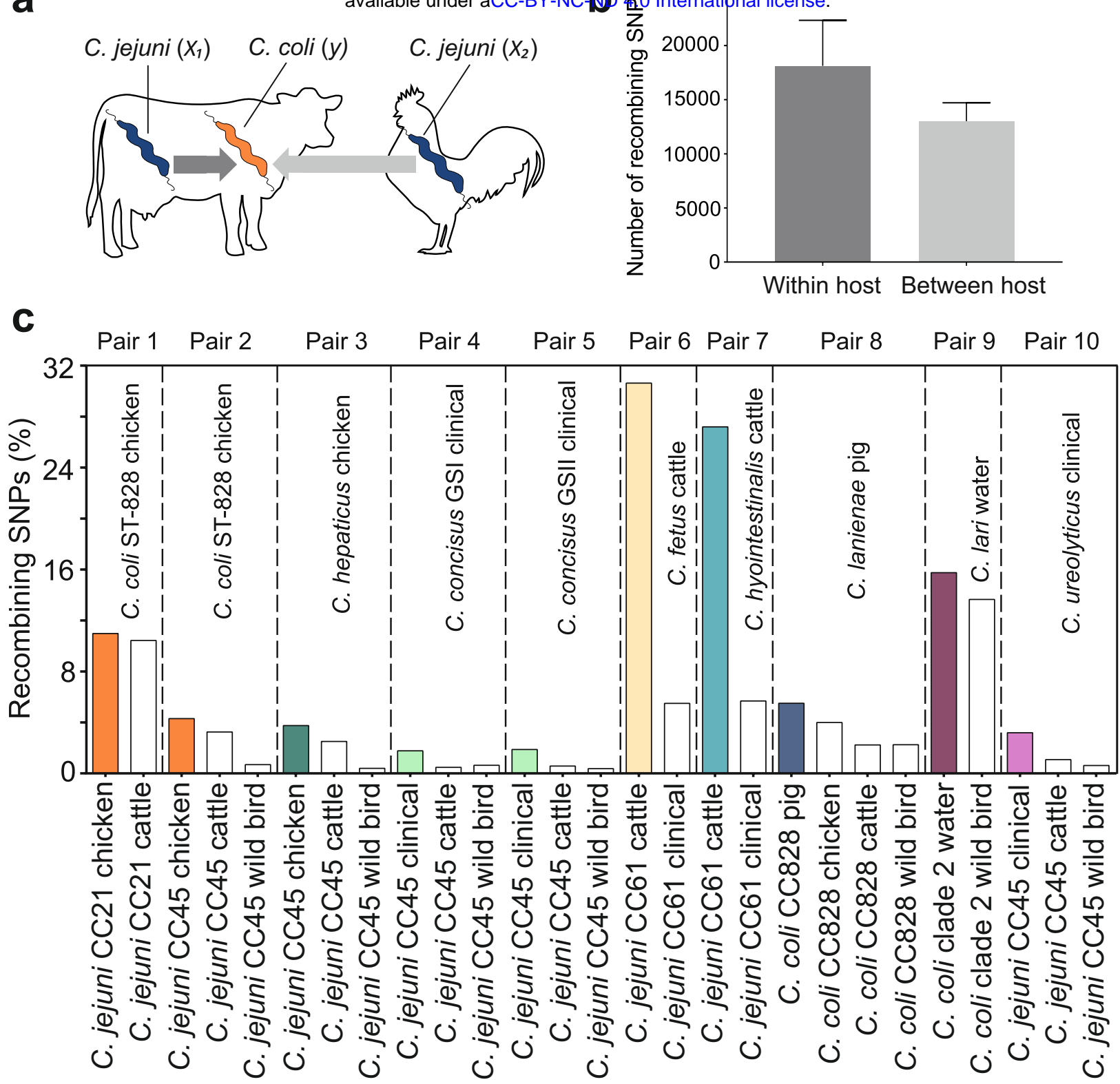
bioRxiv preprint doi: https://doi.org/10.1101/2021.08.24.457495; this version posted August 24, 2021. The copyright holder for this preprint (which was not certified by peer review) is the author/funder, who has granted bioRxiv a license to display the preprint in perpetuity. It is made available under aCC-BY-NC-ND 4.0 International license.

a

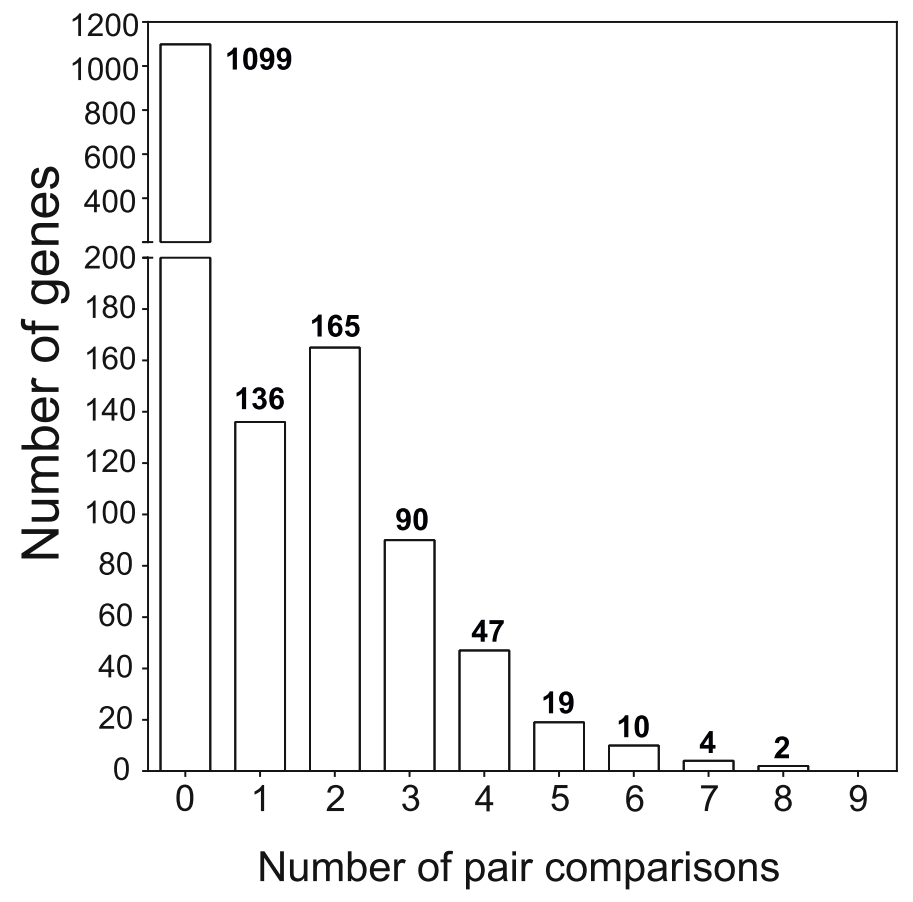

C

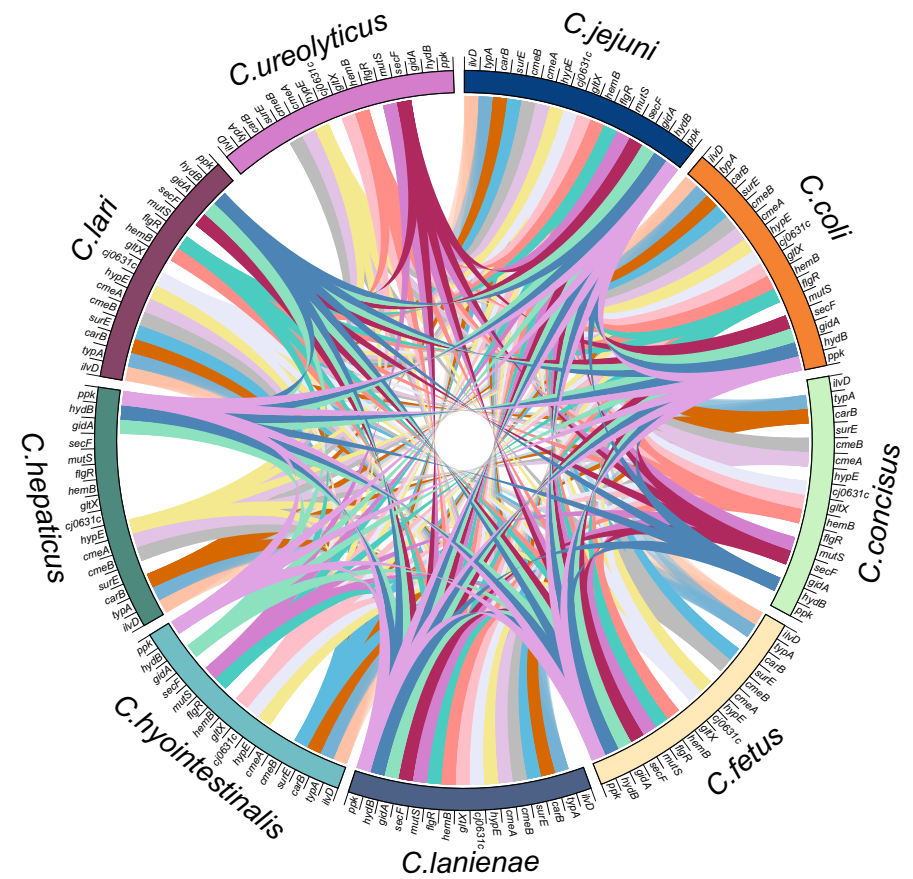

b

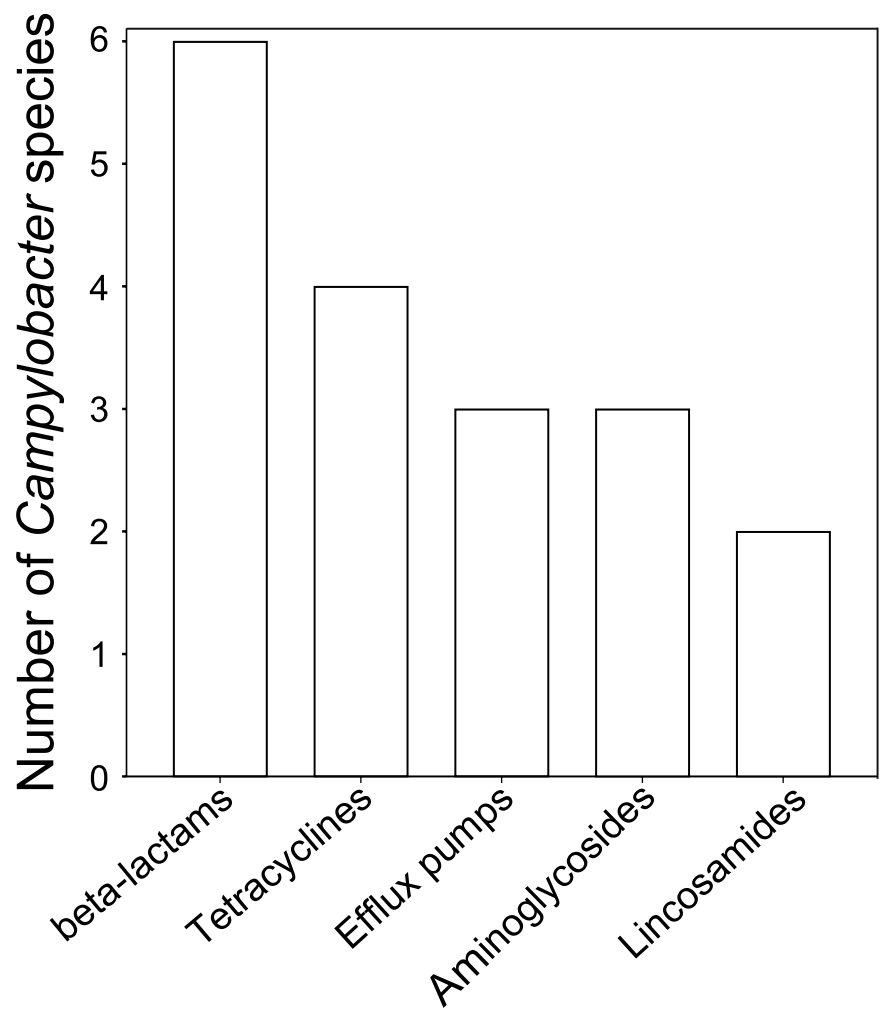

d

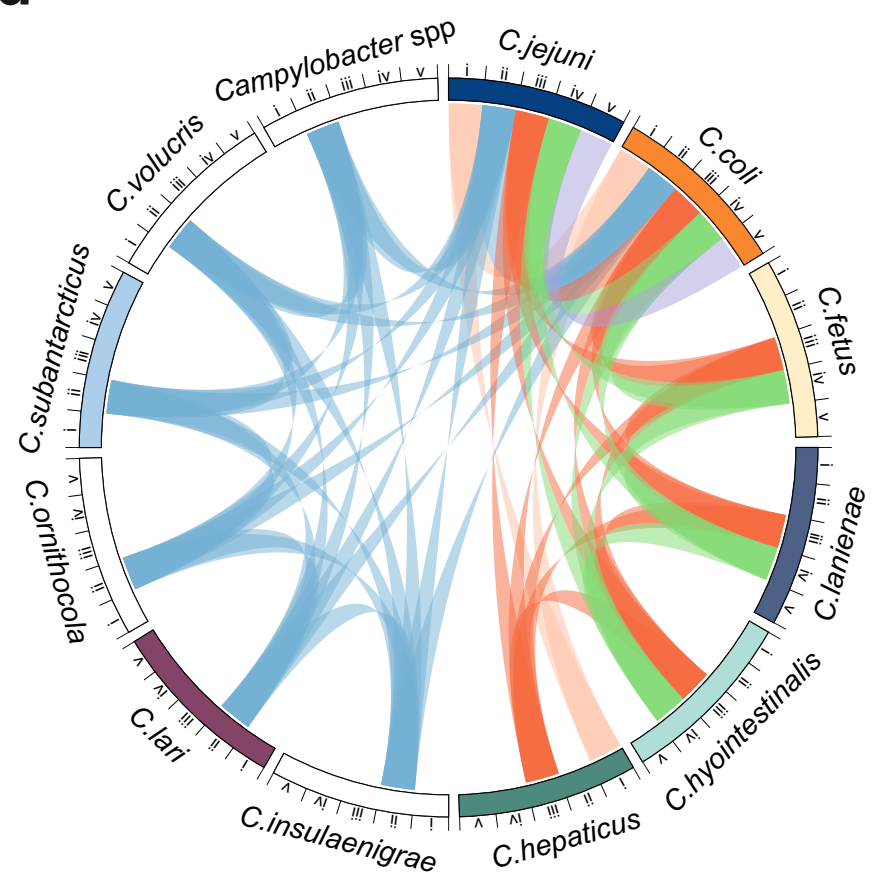

